\title{
DESVELANDO O CUIDADO HUMANIZADO: PERCEPÇÕES DE ENFERMEIROS EM ONCOLOGIA PEDIÁTRICA ${ }^{1}$
}

\author{
Maiara Rodrigues dos Santos², Lucía Silva3, Maira Deguer Misko ${ }^{4}$, Kátia Poles ${ }^{5}$, Regina Szylit Bousso
}

\footnotetext{
${ }^{1}$ Este artigo é baseado em relatório de pesquisa desenvolvida com recursos financeiros do Programa Institucional de Bolsas de Iniciação Científica do Conselho Nacional de Desenvolvimento Científico e Tecnológico.

${ }^{2}$ Doutoranda em Enfermagem da Escola de Enfermagem da Universidade de São Paulo (USP). São Paulo, São Paulo, Brasil. E-mail: maiara.santos@usp.br

${ }^{3}$ Doutora em Ciências. Professora do Curso de Graduação em Enfermagem da Faculdade Marechal Rondon/Universidade Nove de Julho. São Paulo, São Paulo, Brasil. E-mail: luciasilva@usp.br

${ }^{4}$ Doutora em Ciências pela Escola de Enfermagem da USP. São Paulo, São Paulo, Brasil. E-mail: mairadmisko@hotmail.com

${ }^{5}$ Doutora em Enfermagem. Professora da Universidade Federal de São João Del-Rei. São João Del-Rei, Minas Gerais, Brasil. E-mail kpoles@usp.br

${ }^{6}$ Doutora em Enfermagem. Professora Livre-Docente do Departamento de Enfermagem Materno-Infantil e Psiquiátrica da Escola de Enfermagem da USP. São Paulo, São Paulo, Brasil. E-mail: szylit@usp.br
}

RESUMO: Esse estudo teve como objetivos desvelar os elementos do cuidado humanizado presentes no encontro entre enfermeiro, família e criança com câncer, identificar a percepção desses enfermeiros quanto à humanização da assistência e verificar em que situações o enfermeiro percebe que a humanização está ancorada ao cuidado. Trata-se de estudo exploratório-descritivo, com abordagem qualitativa. Utilizou-se como referencial teórico a Teoria do Cuidado Humano de Watson. Os dados foram coletados por meio de entrevista semiestruturada com nove enfermeiros de um hospital público especializado em oncologia pediátrica em São Paulo. Os resultados apontaram para o fenômeno "Desvelando o cuidado humanizado dispensado à família e à criança com câncer". Os elementos teóricos emergiram das descrições de eventos clínicos ou situações apresentadas pelos enfermeiros. Os dados permitiram reflexões sobre possibilidades de construção do processo humanístico interpessoal no ambiente de cuidado na oncologia pediátrica e de avanços e limitações quanto à aplicabilidade deste referencial na prática.

DESCRITORES: Oncologia. Pediatria. Cuidados de enfermagem. Humanização da assistência.

\section{UNVEILING HUMANIZED CARE: NURSES' PERCEPTIONS IN PEDIATRIC ONCOLOGY}

\begin{abstract}
This study aimed to unveil the elements of humanized care present in the encounter between the nurse, the family and the child with cancer, to identify these nurses' perceptions regarding the humanization of the care, and ascertain in which situations the nurse perceives that the humanization is anchored in the care. It is an exploratory-descriptive study with a qualitative approach. Watson's Theory of Human Caring was used as a theoretical framework. The data was collected through semi-structured interviews held with nine nurses from a public hospital specialized in pediatric oncology in São Paulo. The results indicated the phenomenon "Unveiling humanized care given to the child with cancer and her family". The theoretical elements emerged from the descriptions of clinical events or situations presented by the nurses. The data permitted reflection on possibilities for construction of the humanistic interpersonal process in the care environment in pediatric oncology and on advances and limitations relating to the applicability of this framework in practice.
\end{abstract} DESCRIPTORS: Medical oncology. Pediatrics. Nursing care. Humanization of care.

\section{REVELANDO EL CUIDADO HUMANIZADO: PERCEPCIONES DE ENFERMEROS EN UNIDAD DE ONCOLOGÍA DE NIÑOS}

RESUMEN: Este estudio tuvo como objetivos revelar los elementos de la atención humanizada en el encuentro entre enfermero, familia y niño con cáncer, identificar las percepciones de los enfermeros sobre la atención humanizada y comprobar en que situaciones los enfermeros perciben que la humanización se relaciona con el cuidado. Este es un estudio exploratorio-descriptivo, con enfoque cualitativo. Se utilizó como marco teórico la teoría del cuidado humano de Watson. Los datos fueron recolectados a través de entrevistas semi-estructuradas con nueve enfermeras en un hospital público especializado en oncología pediátrica en São Paulo. Los resultados indicaran el fenómeno "Revelando el cuidado humanizado ofrecido a la familia y al niño con cáncer." Los elementos teóricos surgieron a partir de descripciones de eventos clínicos o situaciones presentadas por los enfermeros. Los datos permitieron reflexiones acerca las posibilidades de construir un proceso interpersonal humanista en la oncología pediátrica y los avances y limitaciones en la aplicabilidad de este referencial en la práctica.

DESCRIPTORES: Oncología médica. Pediatría. Atención de enfermería. Humanización de la atención. 


\section{INTRODUÇÃO}

Desde o inicio do século XXI, um forte movimento vinculado à humanização tem permeado discussões na área de saúde. O Ministério da Saúde, em 2000, regulamentou o Programa Nacional de Humanização, que teve como objetivo fundamental o aprimoramento das relações entre profissionais, usuários/profissionais e hospital/ comunidade, visando melhorar a qualidade e a eficácia dos serviços prestados pelas instituições e promover uma nova cultura de atendimento. ${ }^{1}$

Humanização é uma expressão de difícil conceituação, tendo em vista seu caráter subjetivo, complexo e multidimensional. ${ }^{2} \mathrm{~A}$ literatura descreve que "humanizar é afirmar o humano na ação e isso significa cuidado porque só o ser humano é capaz de cuidar no sentido integral" 3:416

Desse modo, além da ênfase para a integralidade da atenção, também deve haver um movimento de reflexão crítica dessas relações, considerando a subjetividade dos indivíduos na ocasião do cuidado. Trata-se de um processo que exige ênfase ampla e coletiva, não apenas do ser cuidado, foco da relação, mas também da preocupação com a estruturação do ambiente e dos profissionais, para que todos usufruam de segurança e conforto. ${ }^{4}$ Além disso, envolve ética e estética, o que pressupõe além da técnica, sensibilidade para que os indivíduos formalizem a consciência com o cuidado. ${ }^{5}$

Nesse sentido, a humanização é um processo complexo, que envolve padrões diferenciados na percepção dos profissionais, seus valores e crenças, para haver mudança de comportamento. Nessa relação única e intersubjetiva tem-se um processo singular, não caracterizado por generalizações, já que diferentes profissionais, equipes e instituições terão processos distintos na aquisição de habilidades para uma assistência mais humanizada como visam os programas emergentes. ${ }^{6-8}$

Esse estudo tem como proposta analisar essa singularidade no processo de humanização, com enfermeiros que trabalham em oncologia pediátrica. Nesse contexto, aliada à estrutura da criança ainda em crescimento e desenvolvimento, tem-se a evolução de uma doença ameaçadora e estigmatizada. Diante disso, a família passa por uma desestruturação, justificada pela mudança na rotina, pelas crenças que cercam a doença e pelo sentimento de indignação ao ver uma criança ser privada dos seus "direitos" em detrimento do sofrimento ocasionado por sucessivas intervenções dentro do hospital, que são grandes geradoras de ansiedade e estresse. ${ }^{9-10}$

Por isso, a criança com câncer e sua família passam por situações de extrema fragilidade física, psicológica e social. ${ }^{11}$ Além do ambiente pouco acolhedor no hospital, os fatores psicológicos que envolvem a criança e a família, como o estresse e a ansiedade durante a internação hospitalar, são identificados como limitantes no cuidado de enfermagem e influenciam a interação do profissional com a família, gerando situações de incompreensão e não cooperação por parte da família nos cuidados.

A enfermagem tem importante papel nesse processo, já que as atitudes de cuidado devem considerar fatores que minimizem essas influências e promovam uma assistência humanizada. Fatores como estabelecer vínculo de confiança e amizade, empatia, fazer com que o paciente sinta-se parte do processo, são elementos que permitem um cuidado além da técnica, considerando a dimensão humana desse processo. ${ }^{12}$

Ao se deparar com esse ambiente, o enfermeiro deve buscar artifícios para cuidar com arte, habilidade empática e muita criatividade. Ademais, o diagnóstico de câncer envolve sentimentos próprios de sofrimento que trazem mudanças profundas na vida das crianças e de suas famílias, por isso, os aspectos socioculturais, emocionais e espirituais devem ser passíveis de cuidados e intervenção, como contextos decisivos na evolução da patologia. ${ }^{10}$

Dessa maneira, é necessário compreender o sentido do cuidado e a subjetividade que envolve esse processo, com atenção especial ao universo da criança, preservando o seu mundo particular e as etapas de desenvolvimento da infância para satisfazer suas necessidades em troca do bem estar, apesar da condição de doença.

Face ao exposto, foram traçados os seguintes objetivos para este estudo: desvelar os elementos do cuidado humanizado prestado à família e à criança com câncer, identificar a percepção dos enfermeiros que trabalham na oncologia pediátrica quanto à humanização da assistência, e verificar em que situações o enfermeiro percebe que a humanização está ancorada ao cuidado prestado.

\section{MÉTODO}

Este estudo trata-se de pesquisa exploratório-descritiva, sustentada pela abordagem qualitativa, que utilizou como referencial teórico os 
pressupostos da Teoria do Cuidado Humano de Jean Watson. ${ }^{13}$

Em 1979, Watson desenvolveu os carative factors, os quais foram revisados em 1985, sendo introduzido o paradigma de Cuidado Transpessoal, que enfoca o ideal moral, o significado da comunicação e do contato intersubjetivo mediante a co-participação do self como um todo. ${ }^{14} \mathrm{Com}$ a evolução da teoria, foi introduzido o clinical caritas processes, que substituíram os carative factors. Esse processo inclui a sacralidade do ser cuidado, a conexão do ser humano para um plano que extrapola o concreto e visual e a proposição do healing para reconstituição do ser como componentes para fundamentar o cuidado. A teoria considera a intersubjetividade enfermeiro-cliente, a partir da ideia de que há sempre influência de um ser sobre outro e está centrada nos conceitos humanísticos do cuidado, olhando para o indivíduo nas dimensões biopsicológica, espiritual e sociocultural. ${ }^{14-15}$

Os participantes compreenderam nove enfermeiros de um hospital público de oncologia pediátrica da cidade de São Paulo, que atenderam aos seguintes critérios de inclusão: ser enfermeiro e ter vínculo na instituição do estudo. Os sujeitos foram esclarecidos sobre sua participação voluntária, sobre a garantia de sigilo das informações e sobre o uso dos resultados apenas para fins científicos. Esses participantes foram identificados por números, para garantir o anonimato.

Ressalta-se que o projeto recebeu parecer favorável do Comitê de Ética em Pesquisa da Instituição (Parecer n. 534/2006), de acordo com a Resolução n. $196,{ }^{16}$ referente à pesquisa com seres humanos e, posteriormente, os dados foram coletados de novembro de 2008 a fevereiro de 2009 , por meio de entrevistas compostas por duas partes, tendo a primeira a finalidade de identificar os sujeitos da pesquisa e a segunda parte foi composta pelas questões semiestruturadas: o que você entende por humanização? Fale-me sobre uma situação em que você acredita ter prestado um cuidado humanizado? O que torna possível o cuidado humanizado as crianças e suas famílias, no contexto da oncologia? As entrevistas foram gravadas em fitas cassete e, para a análise, seu conteúdo foi transcrito na íntegra, sendo utilizada como estratégia a análise de conteúdo, que busca interpretar os dados por meio das etapas: pré-análise e codificação aberta, exploração do material para categorização, tratamento dos dados e interpretação. ${ }^{17}$

\section{RESULTADOS E DISCUSSÃO}

\section{A descrição dos participantes}

Participaram do estudo nove enfermeiros, identificados pelos números em sequência: Enf. 1, Enf. 2, Enf. 3, Enf. 4, Enf. 5, Enf. 6, Enf. 7, Enf. 8 e Enf. 9.

Dos participantes, um era do sexo masculino e oito eram do sexo feminino, com idade variando de 24 a 28 anos. Quanto ao tempo de formação, a média foi de dois anos e quatro meses. O tempo de atuação na área de oncologia pediátrica variou de dois meses a um ano e seis meses. Dos nove entrevistados, três nunca trabalharam em outra área e os outros seis apresentavam diferentes experiências profissionais prévias como: oncologia com adultos, centro obstétrico, unidade básica de saúde, hematologia e diagnóstico por imagens. Das religiões referidas, quatro enfermeiros se declararam católicos, quatro evangélicos e um espírita.

\section{Os depoimentos}

Os elementos teóricos deste estudo emergiram das descrições de situações apresentadas pelos enfermeiros e foram organizados a partir dos 10 Clinical Caritas Processes, segundo a teoria de Jean Watson. ${ }^{13}$

\section{Prática do amor, amabilidade e serenidade no contexto de cuidado consciente}

O cuidado deve ser baseado em um conjunto de sentimentos humanos universais como a bondade, o interesse e a prática do amor por si e pelos outros, sendo assim, o enfermeiro se torna capaz de conectar-se ao outro e com ele. ${ }^{18}$ Nesse sentido, emergiram dos discursos aspectos que centralizam esses sentimentos como fundamentais para a prática de um cuidado humanizado na enfermagem: "Sendo humano, tratar o outro com carinho, amor e respeito" e "Tendo que exercer a profissão com amor, principal fruto para a realização profissional."

Tem que trabalhar com carinho, com amor, que é o principal. Se você não tiver amor, pelo que você faz, pela sua profissão. [...] nunca vai conseguir fazer um trabalho humanizado, vai tornar tudo mecânico. Amor, carinho e dedicação são coisas essenciais para um trabalho humanizado (Enf. 6).

$\mathrm{O}$ amor ao outro, à profissão e a si mesmo é um dos elementos que traz a afinidade exigida para a inter-relação do self do enfermeiro e do self 
do outro (criança, família, comunidade), à plenitude que rege o universo. ${ }^{15}$

\section{Estar autenticamente presente para possibilitar e manter um sistema profundo de crenças e um mundo subjetivo do self e do ser-para-o-cuidado}

A manutenção da fé e o respeito à crença do outro são elementos essenciais para conectar-se um ao outro. ${ }^{18}$ Mostrar aos pais e às crianças que o enfermeiro estará sempre presente, fazendo o melhor, demonstra a importância de assegurar a presença de um profissional competente e comprometido, junto aos pais e às crianças, em todos os momentos do tratamento.

[...] tentar conversar com os pais e falar: olha, está acontecendo isso e a gente está aqui, está tentando. Não desistiremos. Todas as crianças que estão aqui são graves, mas a gente tenta até o final (Enf. 4).

O enfermeiro também para assegurar à família que a assistência prestada é adequada se percebe encorajando a família a ter fé e esperança no tratamento e no profissional. Assim, ajuda no fortalecimento do laço profissional-família e na manutenção da fé e da confiança.

Tentar entender o que está passando na vida dela [família] e conversar, levar para o lado da fé, para quem acredita. [...] falar referente à equipe médica e de enfermagem, que é muito boa, que tem experiência, $e$ tentar dar tranquilidade de que ele vai ser tratado da melhor forma aqui (Enf. 1).

\section{Cultivar suas próprias práticas espirituais $e$} transpessoais de ser além de seu próprio ego, aberto a outros com sensibilidade e compaixão

Nesse processo, Watson enfatiza a necessidade de experenciar emoções e sentimentos nas relações de cuidado, e ainda revela que para haver uma verdadeira interação deve-se agir de modo sensível. É essa sensibilidade que faz o contato transcender o mundo físico/material, para integrar também o mundo emocional e subjetivo. ${ }^{19}$ O enfermeiro acredita que mostrar sensibilidade aos sentimentos das crianças e familiares, reflete a preocupação do profissional em compartilhar esses sentimentos para ter empatia e integrá-los no cuidado como um processo humano, que requer do profissional a habilidade de escutar.

A gente vai puncionar uma veia, rapidamente você punciona! Mas quando o pai quer conversar, quer falar dos problemas da criança. Mesmo nesse momento você ouve; às vezes até você chora junto (Enf. 6).

Saber escolher o momento certo exige do enfermeiro a sensibilidade para identificar quando um momento não é adequado para a realização de um determinado procedimento, especialmente por se tratar de uma criança. Ao mesmo tempo, percebe a necessidade de impor limites à criança, com uma certa tolerância, para não prejudicar a sua saúde durante o tratamento.

Tem que buscar o melhor momento [...]. Tinha uma criança em fase terminal aqui e a gente ia puncionar o cateter, quando ele disse: 'ah tia, espera só um pouquinho?' Então eu falei: tá bom, depois a tia tem que colocar o remédio e puncionar o seu cateter, tá bom? Depois eu esperei uns 30 minutinhos, fiquei lá, conversei, e ele me olhou: 'agora pode, tia'. Então fui lá, puncionei e ele ficou tranquilinho para tomar a medicação (Enf. 6).

\section{Desenvolver e sustentar uma autêntica relação de cuidado, de ajuda e confiança}

Para desenvolver a relação de ajuda e confiança, alguns elementos auxiliam para estabelecer uma interação harmoniosa e cuidadosa. A congruência trata-se de uma das características que ajudam a construir um relacionamento verdadeiro, em que o enfermeiro deve agir de maneira honesta e aberta. ${ }^{19}$ Estabelecer um relacionamento com sinceridade para haver confiança é a forma como o profissional exerce a congruência com a criança, caminhando para além de um trabalho produtivo, porque consegue transcender a rigidez das expectativas da função.

Você conversa antes, explica o que vai acontecer [...] pode ser que doa ou que não! Nunca mentir! A gente que trabalha com criança percebe isso rápido [...]. Assim a gente consegue fazer com que ele entenda e ajude durante o procedimento. Isso é humanizar, é atenção, conversar, ouvir (Enf. 6).

Outra condição essencial para desenvolver a relação de ajuda e confiança é a empatia, explicada como a habilidade do enfermeiro para experenciar o universo privativo do outro, e comunicar-lhe algum grau significativo de compreensão. ${ }^{19} \mathrm{O}$ enfermeiro se percebe olhando para as coisas do ponto de vista da criança e da família, como forma de expressar a empatia, fundamental para o cuidado humanizado.

Eu sempre me coloco no lugar do outro para tudo o que eu faço, não só no trabalho, mas para tudo [...]. A gente tenta entender tudo o que o paciente está passando, para resolver da melhor forma possivel (Enf. 7). 
A habilidade de reconhecer o sentimento do outro é uma referência comum para a experiência emocional. Ainda assim, ninguém pode passar completamente pela experiência do outro, mas algum grau de dor, raiva, tristeza, culpa e prazer, uma pessoa já pode ter sentido alguma vez, e isso embasa uma referência para desenvolver essa sensibilidade, o respeito e a estima. ${ }^{18-19}$

Outra característica nessa relação de ajuda e confiança é a aceitação positiva incondicional, que representa aceitar de forma positiva o outro, por meio de pequenos detalhes como o sorriso, a postura do corpo, o toque carinhoso e a capacidade de ouvir. ${ }^{19}$ Valorizando a comunicação interpessoal representa o movimento do enfermeiro para estabelecer vínculo com a família, com habilidade comunicacional, e realizar um cuidado humanizado, assegurando as necessidades dos pacientes.

Para o cuidado humanizado, a conversa, a comunicação interpessoal é muito importante. Porque, às vezes, dez, vinte minutos conversando, explicando alguma coisa, consolando, ou mesmo nem falando nada, só ouvindo, jáé, para outra pessoa que precisa desabafar, muito, né? [...]. Bastante carinho e paciência para ouvir, eu acho muito importante (Enf. 5).

Esse envolvimento que aproxima o profissional da criança e de sua família, nas situações de câncer, é fruto da construção de uma relação de ajuda e confiança que envolve empatia, congruência e aceitação positiva incondicional e consolida uma referência também nos momentos mais frágeis. Estando disponível ao lado da família nos momentos difíceis representa o envolvimento com os sentimentos dos familiares e a relação próxima estabelecida pelos enfermeiros, como parte do processo de humanização.

[...] tinha morrido a paciente e [...] eu sabia que não ia vê-la ali naquele momento [no velório], ela não ia ver que eu estava lá, mas eu senti a necessidade de dar um conforto para a mãe dela (Enf. 2).

\section{Estar presente e apoiar a expressão de sentimentos positivos e negativos, como uma conexão profunda com o espírito do ser e do ser que cuida do outro}

A aceitação e a expressão de sentimentos deve estar presente para manter um canal de comunicação entre as pessoas. A não expressão daquilo que se sente leva à inconsistência entre pensamentos e sentimentos, o que pode resultar em ansiedade, estresse, confusão, agressivida- de e até mesmo medo. ${ }^{19}$ Dar apoio e respeitar a criança e a família ao expressarem sentimentos de angústia representa o esforço do enfermeiro para compreendê-los e apoiá-los quando apresentam comportamentos de angústia ou raiva. Valorizar sentimentos e expressões de alegria refere-se à importância do enfermeiro enfatizar sentimentos positivos manifestados pela criança e família.

Tem sempre que entender mesmo quando você tem uma criança que chuta e xinga. Você não sabe o que é [...]. Você vê que a mãe está sofrendo: 'vocês estão julgando meu filho e não é assim. Ele está doente, a gente não sabe o que fazer com ele' (Enf. 4).

Os sentimentos justificam pensamentos e comportamentos e, portanto, quem cuida deve estar atento aos sentimentos do outro na manutenção da saúde e na resposta das pessoas à situação de doença, como forma de conexão profunda com o espírito do ser cuidado e do ser que cuida do outro. ${ }^{13,15}$

Uso criativo do ser, de todas as formas de conhecimento e do ser/fazer, como parte do processo de cuidado para engajar na arte da prática do cuidado e proteção

A resolução criativa de problemas deve aliar conhecimento e intuição como parte do processo de cuidar. O método científico para a prática de enfermagem tem igual valor à natureza fundamental da enfermagem (cuidar do outro), que envolve a abordagem humanística. ${ }^{18-19}$ Considerar o universo peculiar da criança para entendê-la, reflete a preocupação de praticar um cuidado voltado para as necessidades da criança, considerando aspectos particulares do desenvolvimento, para melhorar a compreensão e a interação.

Para a criança tudo é novo, tudo é surpresa, mas é só naquele momento também, né? Quando você vai fazer uma punção, é sofrido para ela naquele momento. Depois de cinco minutos ela está pulando! Então, tem que entrar nesse mundo também, que é um mundo que a gente viveu (Enf. 4).

Outro significado identificado nos discursos foi o uso de ferramentas lúdicas para interagir com a criança, e tem semelhança com o que foi colocado anteriormente, já que em ambos notamos a preocupação do profissional em prover uma abordagem diferenciada para a criança ao considerar um cuidado humanizado. Os enfermeiros descrevem estratégias que utilizam para se aproximar do mundo da criança. 
Acho que isso é humanizar o cuidado e a gente faz isso com coisas corriqueiras mesmo, deixando para eles darem injeção na gente, fingir que estão puncionando a veia, e tornar isso um pouco mais tranquilo para eles (Enf. 3).

Engajar-se numa experiência genuína de ensino-aprendizagem que atenda à unidade do ser na tentativa de significar o estar-juntocom à estrutura referencial do outro

O enfermeiro deve se comprometer de maneira genuína em uma experiência prática de ensino-aprendizagem. ${ }^{19}$ Oferecer ao paciente informações necessárias para compreender o tratamento, representa o papel do profissional como educador na tentativa de fazer a criança e a família entenderem cada aspecto relacionado ao tratamento, diminuindo a ansiedade e o estresse decorrente das incertezas e dúvidas. Para o enfermeiro, é necessário promover encontros educativos e discussões com a equipe, para realizar discussões sobre o tratamento, e também sobre aspectos relacionados ao processo de humanização entre os membros da equipe.

Tem que existir discussões dentro da instituição de trabalho [...] para todo mundo crescer junto, porque senão é como eu te falei: fica à critério pessoal; cada um faz o que acha melhor, e isso não tem nada de científico (Enf. 3).

Criar um ambiente protetor em todos os níveis, onde se está consciente do todo, da beleza, do conforto, da dignidade e da paz

Esse processo está relacionado com o ambiente proporcionado pelo enfermeiro para promover e restaurar a saúde e prevenir a doença. ${ }^{19}$ Em quase todos os depoimentos, esses aspectos surgiram como a necessidade de ter uma visão holística da criança e da família. Dessa forma, foi possível identificar a preocupação do profissional em olhar para o paciente como um ser humano completo, mais do que um problema de saúde.

Humanização para mim significa tratar o paciente da melhor maneira possivel, respeitando tanto a parte psicológica, espiritual, biopsicossocial, completo [...], sempre respeitando o paciente como um todo, e não como uma parte doente (Enf. 9).

Para Watson, ${ }^{14}$ essa é a grande diferença entre as perspectivas da ciência tradicional e da ciência humana. A primeira é normativa, reducionista, mecanicista, centrada no método e na doença do corpo físico. A ciência humana não considera o conhecimento como um produto, e sim, como um processo de descoberta, sendo ela transpessoal, metafísica, centrada no fenômeno e a doença vista como resposta às condições humanas pessoais. ${ }^{14}$

Assistir as necessidades humanas conscientemente, com um cuidado humano essencial, o qual potencializa a aliança mente-corpoespírito

Esse processo está baseado em uma hierarquia de cuidados, considerando cada pessoa no contexto global. As necessidades hierárquicas foram compostas da seguinte forma: necessidades de sobrevivência, funcionais, integradoras e de busca de crescimento. Para Watson, ${ }^{14} \mathrm{o}$ atendimento das necessidades de ordem inferior pode não auxiliar o ser humano em direção à autoatualização.

Tem que explicar o que vai acontecer, o que a criança pode ter, que cai cabelo, tem falta de apetite quando faz o tratamento, e cuidar disso também [...]. A gente explica, entende quando ela não quer comer, incentiva, mas não força, porque se ela não quer, não quer mesmo! (Enf. 8).

Os enfermeiros da oncologia pediátrica manifestam a necessidade de um atendimento completo, além das necessidades funcionais ou integradoras - eles apresentam um pensamento holístico para o cuidado da criança e da família. ${ }^{14,19}$

Abertura e atenção para as dimensões espiritual-enigmática e existencial da individualidade da vida de cada um e cuidado da alma do self e do ser-para-o-cuidado

Apesar da importância do aspecto espiritual para a prática do cuidado, esse elemento não emergiu espontaneamente nos discursos obtidos. Tampouco os enfermeiros foram estimulados a falar sobre o assunto, já que não foi explorado esse aspecto dentro dos objetivos do estudo. Porém, o enfermeiro valoriza o vínculo para o reconhecimento do próprio self, da criança e da família, e também como fortalecimento no trabalho profissional. Nesse processo, tentar conhecer a experiência do outro é fundamental.

Teve aquele apego [...] a gente [equipe e família] é uma segunda família, ao mesmo tempo que ele [criança] foi a óbito, esse sentimento criado foi algo que me conforta e me dá ânimo pra continuar a trabalhar (Enf. 8).

Apesar disso, parece-nos que falta habilidade para ajudar o paciente e a família a explorar os significados que dão à experiência de doença e 
morte, na dimensão espiritual dentro do contexto da oncologia.

A percepção do enfermeiro sobre o cuidado humanizado traz elementos fundamentais para as relações humanas e estão consistentes com os processos caritas de Jean Watson, ${ }^{19}$ bem como com a discussão acerca do cuidado e humanização, que vem crescendo com a Política Nacional de Humanização (Humaniza/SUS), ${ }^{1}$ enfocando aspectos como: a individualidade das pessoas, a escuta atenta, a valorização das crenças, da comunicação e a presença genuína. ${ }^{6}$ Considerando os relacionamentos humanos como manifestação de subjetividades, esses ingredientes fazem parte da sensibilização dos profissionais e das instituições para enraizar o aspecto existencial e humano nos encontros de saúde. Sendo assim, o foco de um constante trabalho de conscientização das equipes é necessário, incluindo também um cuidado com o profissional, para o atendimento da criança e da família, visto que as rotinas hospitalares são rígidas e ainda se distanciam das necessidades das famílias. ${ }^{6,20}$

Um referencial teórico como a teoria do cuidado humano de Jean Watson, para a prática do cuidado prestado às crianças e famílias que enfrentam o câncer, é um norteador para a prática do enfermeiro e importante recurso para extrapolar a rigidez das funções que engessam o encontro de cuidado, promovendo, assim, um diálogo mais sensível às necessidades humanas físicas, biológicas, psicológicas, emocionais e espirituais.

\section{CONSIDERAÇÕES FINAIS}

A Teoria de Jean Watson nos leva a pensar na existência do ser, no amor como manifestação de cuidado que transcende o aspecto físico desse processo. Ao utilizarmos os dez elementos que compõem o processo clinical caritas, entendemos que o enfermeiro precisa se arriscar a realizar uma análise, uma transformação em seu próprio íntimo, para que seja possível a promoção do cuidado humanístico.

Esse cuidado envolve o fortalecimento do vínculo entre o profissional, a família e a criança. Alguns sentimentos precisam estar evidentes, como carinho, amor e respeito pelo outro e pela profissão. Da mesma forma, é necessário empenhar-se para estabelecer um relacionamento com empatia e criatividade, encorajar a fé e a esperança no tratamento, agir com sensibilidade e flexibilidade na abordagem com a criança, aceitar a ex- pressão de sentimentos, investir na comunicação e realizar reuniões com a equipe para pensar no cuidado oferecido, a fim de assegurar da melhor forma as necessidades da família. Sendo assim, o enfermeiro exibe um papel fundamental para garantir que o encontro de cuidado envolva consciência e sensibilidade na interação com o outro.

O enfermeiro que vivencia o contexto da oncologia pediátrica conhece elementos humanos essenciais para tornar o cuidado mais próximo do cliente, tal como preconiza a Teoria de Watson, porém pouco se apropria de referenciais para o cuidado. Assim, torna-se mais difícil conciliar estratégias formais e embasadas para ajudar no sofrimento de crianças e famílias. Essa teoria, por se aproximar da percepção de cuidado humanizado trazida pelos enfermeiros, pode ser um caminho para que esses profissionais desenvolvam intervenções no atendimento das necessidades e ajustamentos da família à doença.

A subjetividade das ações de cuidado envolve um olhar para as interações humanas, que estão em constante mudança, exigindo preparo e reflexão crítica dos profissionais que promovem os momentos de cuidado. Este estudo abre essa possibilidade a partir do conhecimento da percepção e da vivência do enfermeiro no cuidado às crianças e às famílias que vivem a experiência do câncer. Trata-se de um convite à reflexão e uma proposta de mudar o jeito de pensar enfermagem, através da valorização e da percepção do outro e de si mesmo na relação de cuidado.

O décimo processo clinical caritas - A permissão de forças existentes/fenomenológicas espirituais - nos parece relevante para o contexto da oncologia, no qual os enfermeiros lidam com as questões de vida e morte. Segundo Watson, se os enfermeiros não forem capazes de olhar para o seu interior e encarar suas próprias questões relacionadas às perdas, não serão capazes de ajudar o outro a descobrir o significado evento difícil que vivenciam. Assim, consideramos esse processo preponderante para o verdadeiro cuidado humanístico, especialmente nos contextos em que precisamos lidar com pessoas no processo de morrer.

"Desvelando o cuidado humanizado: percepções de enfermeiros em oncologia pediátrica" representa o exercício intelectual realizado no percurso deste trabalho, de aprofundar o conhecimento na Teoria do Cuidado Humano de Jean Watson e analisar os depoimentos tendo como base este referencial. Este estudo trouxe-nos 
um novo conhecimento em relação ao cuidado e que, sem dúvida, trará grandes benefícios aos nossos futuros clientes e famílias, alvo das ações de cuidar.

\section{REFERÊNCIAS}

1. Ministério da Saúde (BR). Manual do Programa Nacional de Humanização da Assistência Hospitalar. Brasília (DF): Ministério da Saúde; 2005 [acesso 2010 Ago 11]. Disponível em http:/ / www.saude.sp.gov. br/resources/gestor/ acesso_rapido/auditoria/ manual_PNHAH.pdf

2. Simões ALA, Rodrigues FR, Tavares DMS, Rodrigues LR. Humanização na saúde: enfoque na atenção primária. Texto Contexto Enferm. 2007 Jul-Set; 16(3):439-44.

3. Waldow VR, Borges RF. Cuidar e humanizar: relações e significados. Acta Paul Enferm. 2011 JanFev; 24(3):414-8.

4. Waldow VR. Uma experiência vivida por uma cuidadora, como paciente, utilizando a narrativa literária. Texto Contexto Enferm. 2011; 20(4):825-33.

5. Waldow VR. Atualização do cuidar. Arquichan 2008 Abr; 8(1):85-96.

6. Deslandes S. Humanização: revisitando o conceito a partir das contribuições da sociologia médica. In: Deslandes SF, organizadora. Humanização dos cuidados em saúde: conceitos, dilemas e práticas. Rio de Janeiro: Editora Fiocruz, 2006. p.33-47

7. Martins JJ, Albuquerque GL. A utilização de tecnologias relacionais como estratégia para humanização do processo de trabalho de saúde. Cienc Cuid Saude 2007 Jul-Set; 6(3):351-6.

8. Ayres JRCM. Uma concepção hermenêutica de saúde. Physis - Rev Saúde Coletiva 2007 Abr; 17(1):43-62.

9. Oliveira NFS, Costa SFG, Nóbrega MML. Diálogo vivido entre enfermeira e mães de crianças com câncer. Rev Eletr Enf [Internet]. 2006 [acesso 2012 Nov 05]; 8(1):99-107. Disponível: http://www.fen. ufg.br/fen_revista/revista8_1/pdf/v8n1a14.pdf

10. Ortiz MCA, Lima RAG. Experiências de familiares de crianças e adolescentes, após o término do tratamento contra câncer: subsídios para o cuidado de enfermagem. Rev. Latino-Am Enfermagem. 2007 Maio-Jun [acesso 2012 Nov 05]; 15(3). Disponível em: http://www.scielo.br/pdf/rlae/v15n3/ pt_v15n3a08.pdf

11. Maranhão TA, Melo BMS, Vieira TS, Veloso AMMV, Batista NNLAL. A humanização no cuidar da criança portadora de câncer: fatores limitantes e facilitadores. J Health Sci Inst. 2011 Abr; 29(2):106-9.

12. Amador DD, Gomes IP, Coutinho SED, Costa TNA, Collet N. Concepção dos enfermeiros acerca da capacitação no cuidado à criança com câncer. Texto Contexto Enferm. 2011 Jan-Mar; 20(1) 94-101.

13. Watson J. Watson's theory of human caring and subjective living experiences: carative factors/caritas processes as disciplinary guide to the professional nursing practice. Texto Contexto Enferm. 2007 JanMar; 6(1):129-35.

14. Watson J. Nursing: human science and human care: a theory of nursing. $2^{\text {nd }}$ printing. New York (US): National League for Nursing; 1985.

15. Favero L, Meier MJ, Lacerda MR, Mazza VA, Kalinowski L. Aplicação da Teoria do Cuidado Transpessoal de Jean Watson: uma década de produção brasileira. Acta Paul. Enferm. 2009 MarAbr; 22(2):213-8.

16. Ministério da Saúde (BR), Conselho Nacional de Saúde, Comissão Nacional de Ética em Pesquisa. Resolução No 196 de 10 de outubro de 1996: diretrizes e normas regulamentadoras de pesquisa envolvendo seres humanos. Brasília (DF): MS; 1996.

17. Bardin L. Análise de conteúdo. Lisboa (PT): Edições 70; 2008.

18. Watson J. Caring as the essence and science of nursing and health care. O Mundo da Saúde 2009 Mar; 33(2):143-9.

19. Watson J. Nursing: the philosophy and science of caring. Boulder (US): University Press of Colorado; 2008.

20. Morsch DS, Aragão PM. A criança, sua família e o hospital: pensando processos de humanização. In: Deslandes SF, organizadora. Humanização dos cuidados em saúde: conceitos, dilemas e práticas. Rio de Janeiro (RJ): Fiocruz, 2006. p.235-60. 